\title{
Música, transmodalidad e intersubjetividad
}

\author{
FAVIO SHIFRES \\ Universidad Nacional de La Plata

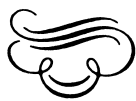

Resumen

Este artículo propone que la ejecución musical puede entenderse como una experiencia intersubjetiva en la que los significados que emergen de ella se vinculan a cómo se configura en el tiempo y se comparte esa configuración temporal. En tal sentido, se argumenta que es la perspectiva de intersubjetividad de segunda persona la que mejor explica la experiencia musical. El fenómeno de transmodalidad se halla en la base de los intercambios emocionales que conforman las experiencias de intersubjetividad clásicas. En este trabajo se presenta un experimento que aporta evidencia de transmodalidad en la ejecución musical. En ella, las sutilezas de las tensiones temporales entre la estructura de la composición y sus desvíos en la ejecución expresiva son análogas a las filigranas temporales que promueven los estados de mutualidad tanto en la temprana infancia como en otras experiencias intersubjetivas en la vida adulta. Los resultados se discuten en vinculación ciertas hipótesis sobre el poder comunicacional que tiene la regulación temporal en la ejecución musical expresiva.

Palabras clave: Intersubjetividad, perspectiva de segunda persona, transmodalidad, música y cine.

\section{Music, crossmodality and second person intersubjectivity}

\begin{abstract}
The paper proposes that music performance may be understood as an intersubjective experience in which emergent meanings are related to the way in which it is configured over time and that temporal configuration is shared. It is thus argued that second person intersubjectivity is the approach that best explains musical experience. From this perspective, the crossmodal phenomenon is a vital part of emotional exchanges making up classic intersubjective experiences. An experiment providing evidence of crossmodality in music performance is presented. Details of the contrast between structural compositional time and its deviations in expressive performance are analogous to temporal filigrees that uphold states of mutuality both in early childhood and in other intersubjective experiences during adult life. These results are discussed in light of certain bypotheses dealing with the communicational power of timing in expressive music performance.

Keywords: Intersubjectivity, second person perspective, crossmodality, music and film.
\end{abstract}

Correspondencia con el autor: Fray Justo Santamaría de Oro 2260. C1425FOF Buenos Aires (Argentina). Tel: 54 11-4775 7899. E-mail: favioshifres@saccom.org.ar 
... una nueva floración de un nuevo arte, que derrote para siempre la fijeza del icono que refleja la verdad revelada una sola vez y para siempre, y en cambio revele un nuevo conocimiento que se despliegue en todos los sentidos y para goce de todos los sentidos...

Carlos Fuentes (1975)

\section{INTRODUCCIÓN}

En la cultura musical académica occidental, la tarea de componer música está claramente separada de la de ejecutarla. Aunque una misma persona pueda frecuentemente realizar ambas es común que los ejecutantes interpreten composiciones de otras personas. Los oyentes solemos además preferir a un intérprete para una determinada composición. De modo que somos sensibles a los rasgos que el intérprete es capaz de aportar a través de su ejecución. Las ejecuciones que preferimos son aquellas que nos cautivan, nos conmueven, nos sorprenden por su expresión. Una ejecución expresiva se diferencia de otra en un conjunto de sutiles modificaciones en la regulación temporal, la dinámica, la afinación, el vibrato y la articulación de los sonidos organizadas como un todo de manera sistemática y coherente al que se suele denominar microestructura expresiva (Clynes 1983). Así, la microestructura expresiva es considerada como "lo que aporta el ejecutante". Aunque no seamos siempre concientes de ello, esas microvariaciones pueden hacer que dos ejecuciones de una misma composición -es decir, de una misma estructura composicional, o "lo que aportó el compositor"- nos resulten totalmente diferentes. Pueden lograr que una nos conmueva hasta las lágrimas y otra nos llene de tedio. Pero, ¿cómo puede una ejecución musical afectarnos tan hondamente?

Obviamente, el asombroso impacto que tienen estas nimias acciones en nuestro mundo emocional ha formado parte de la agenda de la psicología de la música desde sus comienzos. Desde esos orígenes el conjunto de rasgos expresivos fue estudiado como algo que "nos llega". Por ello, la psicología cognitiva de la música ha tratado de explicar la tan cautivante, conmovedora y sorprendente experiencia desde la perspectiva comunicacional clásica. Esta perspectiva es la que toma la metáfora de la transmisión de la información como modelo (Shannon y Weaver 1949) y establece que para que tenga lugar la comunicación debe existir un emisor, un canal (por el que circula un mensaje) y un receptor. Además, con el fin de atravesar el canal, la información que circula es a menudo transformada o codificada por el emisor en algún formato proposicional, y descodificada para su recepción. De modo que también debe haber un código común establecido entre emisor y receptor. Un inmenso cuerpo de investigación en ejecución musical ha abordado la comunicación entre ejecutantes y oyentes desde este marco (Gabrielsson, 2001; Hargreaves, McDonals y Miell et al., 2005; Juslin, 1997, 2005; Kendall y Carterette, 1990; Palmer, 1997; Sundberg 1993; Sundberg, Friberg y Fryden, 1991). De acuerdo a ellos, la microestructura expresiva se ajusta a un código que vincula cada los rasgos de la estructura de la composición con la experiencia del oyente. Sin embargo, la musicología contemporánea nos viene alertando sobre la necesidad de que cualquier estudio en ejecución musical valore a la audiencia en vez de considerarla como el último eslabón en una cadena. Bajo esta mirada, la ejecución no es un acto solitario, y sólo puede ser justipreciado en tanto sea considerado como proceso que involucra a la audiencia como componente activo. Los significados de la ejecución musical son interpersonales, y se configuran en cada momento.

¿En qué consiste el significado de este encuentro humano que es una actuación musical?(...) El acto de musicar crea entre los asistentes un conjunto de relaciones, y es en estas relaciones donde se encuentra el significado del acto de musicar. Se encuentra no sólo en las relaciones 
entre los sonidos organizados que generalmente creemos ser lo esencial de la música, sino también en las relaciones que se hacen entre persona y persona en el espacio de la actuación. (Small, 1999; s.p.)

Este es el alcance que tendrá, a lo largo de este trabajo, la expresión ejecución musical. Por ello no debe entenderse bona fide como tradicionalmente es considerada, limitada a la acción y el pensamiento de una persona, independientes del tejido interpersonal en el que tienen lugar. En este contexto, las acciones de todos los involucrados en dicha trama son relevantes para la definición misma de ejecución musical y por ende para la configuración de los contenidos que circulan entre ellos.

El valor de la acción conjunta y del momento presente que la musicología actual pretende rescatar para la ejecución musical la deporta de la tierra de la fantasía de eternidad y le adjudican significados evanescentes que difícilmente puedan ser mapeados en la estructura composicional o en la microestructura expresiva. De este modo, una exégesis psicológica de la ejecución musical desde la metáfora de la transmisión de la información aparece como excesivamente reduccionista. En los estudios en comunicación no verbal (v.g. en primates) o preverbal (v.g. en temprana infancia) en los que el contenido de la información no necesariamente adquiere un formato proposicional, este paradigma viene siendo crecientemente desplazado por otro modelizado por la metáfora de la danza (Shanker y King, 2001). La metáfora de la danza localiza la comunicación en el sostén del sentimiento del ritmo y del movimiento compartido. En ella resulta importante tanto la acción conjunta en sí misma como la organización temporal de esa acción conjunta. Más que las particularidades del procesamiento de la información, es el sentimiento de una acción compartida en el tiempo lo que posibilita la comunicación. De acuerdo con esto, propongo que la ejecución musical puede ser entendida como una experiencia intersubjetiva. El desarrollo de la hipótesis requiere, en primer lugar, delimitar la perspectiva de intersubjetividad desde la cual considerar a la ejecución musical como tal y, en segundo término, encontrar en la ejecución rasgos que caractericen en general a las experiencias de intersubjetividad. El objetivo de este trabajo es justamente desarrollar ambas tareas. La siguiente sección define el alcance del término intersubjetividad que propongo como más adecuado para caracterizar la experiencia de la ejecución musical tal como es entendida por la musicología actual. A partir de ahí, discuto algunos rasgos definitorios de las experiencias de intersubjetividad de segunda persona en particular la estructuración transmodal del tiempo en la interacción identificables en el fenómeno de entonamiento y en la noción de afectos de la vitalidad o sentimientos temporales (tal como son propuestos por Daniel Stern 1985). Luego presento un experimento que aporta evidencia de dicha experiencia temporal transmodal en la ejecución musical. Finalmente relaciono los resultados obtenidos con una teoría sobre el poder comunicacional de la regulación temporal en la ejecución musical expresiva (Shifres, en prensa).

\section{INTERSUBJETIVIDAD DE SEGUNDA PERSONA Y EJECUCIÓN MUSICAL}

Según Nelson Coelho y Luiz Figueiredo (2003) la literatura específica brinda al menos tres significados diversos de la noción de intersubjetividad: (i) el sentido de comunión interpersonal entre sujetos que ajustan tanto sus estados emocionales como sus expresiones respectivas uno a otro; (ii) aquello que define la atención conjunta a objetos de referencia en un dominio compartido de conversación lingüística o extra lingüística, y (iii) la capacidad de inferencia acerca de las intenciones, creencias y sentimientos de otros, y que abarca la simulación o la 
capacidad para "leer" los estados mentales y procesos de los otros (remitiendo al concepto clásico de empatía). La filosofía de la mente y la psicología han discutido diversos modos de comprender la intersubjetividad. Sintéticamente, es posible decir que para algunos la intersubjetividad se basa en capacidades simulativas, es decir en la aptitud para figurarse estar en el lugar del otro y proyectar las propias motivaciones y reacciones, a partir del conocimiento de sí mismo, en las acciones de los demás. Por el contrario, para otros intersubjetividad implica el despliegue de capacidades teoréticas, es decir aquellas que permiten especular acerca de las acciones de los demás en términos teóricos a través de la construcción de argumentos que permiten suponer sus motivaciones y predecir sus reacciones ${ }^{1}$. Sin embargo, la definición de experiencia intersubjetiva como constituida por aquello que "es vivido simultáneamente por varias (dos o más) mentes." (Coehlo y Figueredo 2003; p. 196) conduce a una noción que se apoya más en formas de prácticas corporizadas que son emocionales, sensorio motoras, perceptuales y no conceptuales (Gallagher 2001). En esta línea Trevarthen y Hubley (1978) propusieron que intersubjetividad implica compartir deliberadamente experiencias sobre los acontecimientos y las cosas. Explorada particularmente en la interacción entre el adulto y el infante durante la temprana infancia, esta perspectiva, denominada de segunda persona, supone un marco interactivo basado en una cognición perceptual (visual, auditiva, etcétera) (Gomila, 2003). La acción interpersonal se constituye en la vía por la que alcanza la otra subjetividad. Desde este punto de vista las experiencias de intersubjetividad

...corresponden a situaciones de interacción cara a cara (aunque puede activarse en situaciones artificiales, como el cine, en donde se alteran algunas de las condiciones), se basan en aspectos expresivos (posición corporal, orientación, tono de voz, configuración facial, sonrojo, lágrimas...) que son percibidos directamente como significativos y no como síntomas que hay que interpretar, y cuyo resultado atributivo no se formula concientemente ni requiere una metarrepresentación conceptual, sino que constituye la base de una reacción correspondiente, que tiene su pleno sentido justamente dentro de la situación de interacción. (Gomila, 2003, p. 209)

Por lo dicho, este enfoque se centra principalmente en la atribución de aspectos del mundo emocional de los individuos involucrados en la interacción, lo que permite dotar a la expresión de cualidades comunicacionales.

... (Estos) modos de atribuir emociones (...), presuponen su carácter expresivo, y por lo tanto, perceptible a través de una serie de configuraciones y relaciones (...) Percibimos los diversos aspectos expresivos como una 'Gestalt', como un todo significativo. Esto supone que los estados mentales que captamos a través de la segunda persona son estados expresivos, configuraciones corporales (...) (L)os estados mentales que atribuimos de esta manera son constitutivamente corporales, o bien a la inversa, (...) las actitudes y configuraciones corporales son también mentales. (Gomila, 2003, pp. 210-211)

Sin embargo, no se trata de captar una cierta información perceptual y procesarla categóricamente como correspondiente a tal o cual estado emocional. Por el contrario, la característica distintiva de los estados expresivos que adquieren aquí cualidades comunicacionales es la de presentarse como estados dinámicos que se configuran de un modo particular en el transcurso del tiempo. Esto es lo que Daniel Stern (1985) denominó sentimientos temporales o afectos de la vitalidad. Los afectos de la vitalidad constituyen una cualidad afectiva de la experiencia que no puede ser descripta sino a través de una terminología ad hoc que incluya referencias dinámicas y cinéticas “tales como 'agitación', 'desvanecimiento progresivo', 'fugaz', 'explosivo', 'crescendo', decrescendo', 'estallido', 'dilatado', etcétera” (p. 75). Esto modos de sentir forman parte de todos los procesos vitales, por lo que están presentes en toda nuestra experiencia. Los experimentamos internamente y en el mundo que nos rodea a través de cómo lo percibimos. Los afectos de la vita- 
lidad modelan nuestra experiencia del tiempo porque sus niveles de activación (su intensidad y urgencia) están sometidos a fluctuaciones conforme transcurre el tiempo. Esto es lo que Stern denominó perfiles de activación o la intensidad de la sensación como función del tiempo. Es el mundo emocional de los afectos de la vitalidad el que se comparte con el otro. Por lo tanto es el perfil de activación -el desarrollo temporal de la activación emocional- lo que somos capaces de aparear y compartir en la experiencia intersubjetiva. Notablemente, el infante es capaz de realizar este apareamiento porque puede traducir la información temporal de una modalidad perceptual a otra. Mediante este apareamiento transmodal es posible, por ejemplo, reconocer la analogía temporal entre una pauta auditiva y otra visual. Las propiedades temporales que son reconocidas como análogas son la duración, el pulso y el ritmo.

Dentro del repertorio de rasgos presentes en la perspectiva de segunda persona es posible incluir un fenómeno que resulta crucial en el establecimiento del estado intersubjetivo: el entonamiento ${ }^{2}$. El entonamiento se basa en el establecimiento de relaciones entre conductas explícitas a través de la reproducción de ciertos rasgos temporales y expresivos de una conducta manifiesta que no constituye una imitación abiertamente explícita. Se trata entonces de una manifestación de la relación interafectiva que se caracteriza por (1) la presencia de cierta forma de apareamiento conductual que no es una traducción fiel o imitación; en la que (2) las conductas apareadas se vinculan a diferentes modalidades perceptuales por lo que el proceso de entonamiento en sí se considera un proceso transmodal; y en la cual (3) el objeto del apareamiento no es la conducta en sí sino algún aspecto de la misma que refleja un estado emocional. Por ello se dice que la referencia del apareamiento es el estado emocional y no el acontecimiento conductual externo. Es "la conducta como expresión” y no como signo codificado (Stern, 1985, p. 177).

El entonamiento forma parte del repertorio de conductas que integran la parentalidad intuitiva (Papou?ek 1996). Es decir que es llevado a cabo por los adultos en presencia de los infantes. Sin embargo es posible pensar en dos derivaciones de este marco. En primer lugar es razonable suponer que nuestra capacidad para entonar con las conductas del bebé se extiende a otros tipos de relaciones e interlocutores. Silvia Español y yo (2003) observamos que un niño de 19 meses era capaz de entonar, esto es de reproducir los rasgos temporales y expresivos de la conducta que observaba sin imitarla abiertamente. Por ejemplo, el pequeño realizaba sistemáticamente el gesto de fruncir el ceño al tiempo que giraba su cabeza de acuerdo a la estructura de la música que acompañaba las acciones de un conjunto de danza flamenca que observaba a través de un video. En segundo lugar, posiblemente del mismo modo, muchos de los gestos espontáneos que realizamos cuando escuchamos música así como la multiplicidad de movimientos invisibles producto de las tensiones y relajaciones no controladas llevada a cabo en presencia de la música tengan relación con el entonamiento, habida cuenta que es un proceso que se produce sin percatación conciente.

El concepto de entonamiento renueva la idea clásica de comunicación. Abandonamos la idea de la construcción de un código que pertenece a una modalidad sensorial determinada (visual, auditiva, lingüística, etcétera) para explorar una multiplicidad de modalidades que permiten un acercamiento mutuo. De este modo, "los patrones de comunicación no sólo reflejan cada una de las conductas específicas del otro sino también pueden entonar con otro transmodalmente" (Shanker y King, 2002).

Como se puede apreciar, la perspectiva de segunda persona se apoya intensamente en la transmodalidad. Tal como la trata la psicología del desarrollo, esta noción remite a la capacidad del infante para transferir la experiencia de una 
modalidad perceptual a otra. En el campo de la psicología del arte, la noción aparece desde antaño esbozada en el concepto de sinestesia. Sin embargo, la sinestesia no depende del componente temporal que resulta ser el rasgo definitorio de la transmodalidad.

Si procuramos mostrar que la experiencia intersubjetiva comprometida en la ejecución musical -en el sentido interpersonal en el que fue definida arribadebería ser entendida desde la perspectiva de segunda persona, entonces tendríamos que ser capaces de dar cuenta de la capacidad de quienes participan en ella (ejecutantes y audiencias) para transferir transmodalmente los rasgos de la microestructura expresiva. En la siguiente sección se reporta un experimento realizado con el objeto de demostrar la experiencia transmodal que el oyente puede tener en la ejecución musical.

\section{EL EXPERIMENTO}

\section{Fundamento}

Muchas experiencias transmodales se basan en la existencia de una estructura temporal análoga que se erige como nexo relacional entre las diferentes modalidades perceptuales (Lewkowicz, 1992). Esa analogía puede abarcar cualquiera de los tres atributos de la temporalidad del estímulo: duración, proporción y ritmo. En los estímulos complejos, diversos atributos del estímulo pueden contribuir a configurar diferentes temporalidades. En el cine, por ejemplo, sonido e imagen pueden proveer estructuras temporales concordantes, brindando un alto grado de integración perceptual a través de esa redundancia transmodal. La redundancia transmodal favorece la comunicación y la comprensión de los fenómenos complejos (Lewckowicz y Kraebel 2004). En la ejecución musical, la estructura composicional y la microestructura expresiva también pueden vincularse de manera de suscitar organizaciones temporales concordantes o discordantes. Muchas veces el ejecutante utiliza esta capacidad para poner de manifiesto algún aspecto estructural de la composición. Un sencillo ejemplo -tal vez excesivamente ingenuopuede contribuir a aclarar este punto. Si tenemos una composición ("lo que hizo el compositor") con una melodía cuyas frases se organizan en unidades de cuatro tiempos, que a su vez es acompañada por una armonía que cambia cada dos tiempos, existe una alta probabilidad de que ocurra en la microestructura ("lo que hace el ejecutante") contribuya de alguna de estas formas: (i) haciendo uso de sutiles fluctuaciones de tempo, alargamientos y acortamientos de las notas, con el objeto de frasear cada cuatro tiempos; o (ii) enfatizando dinámicamente (acentuando) el cambio armónico, cada dos tiempos. En el primer caso, la microestructura expresiva estaría brindando información redundante relativa a la organización cada 4 tiempos. En el segundo la redundancia sería sobre la organización cada 2 tiempos. Por ello decimos que particularmente en la ejecución actual de la música académica del siglo XIX es posible que la acción del ejecutante sobre la composición musical provea grados de complejidad y redundancia, que contribuyan a organizar la experiencia temporal de la obra musical (en tanto ejecución) como un todo, similares a los que proveen las manifestaciones explícitamente multimodales (como el caso del cine). De este modo se puede hipotetizar que la microestructura expresiva coadyuva con la estructura de la composición a la configuración de una experiencia temporal compleja tal como ocurre en fenómenos multimodales. No obstante, tal como ocurre en el cine, la relación entre las diversas configuraciones temporales podría suscitar una suerte de tensión temporal, sobre la que al menos una parte importante del contenido emocional se apoyaría (Shifres, 2007). Para que esta tensión tenga lugar el oyente debería contrastar el tiempo de la microestructura expresiva con el tiempo de la estructura composicional. 
En ese caso, el grado de redundancia provisto por la estimulación multimodal sería reemplazado en la ejecución musical instrumental por los acuerdos entre la estructura composicional y la información expresiva (en términos de rubato, dinámicas, articulaciones, etcétera); una suerte de redundancia intramodal.

Si una cierta secuencia fílmica y una ejecución musical suscitan experiencias temporales análogas es dable esperar que sean consideradas como más afines que si no lo hicieran. Es común que música e imagen presenten en el lenguaje cinematográfico un cierto grado de concordancia que puede ser analizada de múltiples maneras. Tradicionalmente, los estudios que abordan esta concordancia se muestran interesados en el modo en el que la música contribuye a la comprensión del componente visual (Cook, 1998; Lipscomb y Tolchinsky, 2005). Aunque el objetivo aquí es otro (analizar cómo la imagen provee información que puede ser transmodalmente comprendida en términos de la expresión musical) tales estudios contribuyen con marcos conceptuales útiles. Por ejemplo, siguiendo a Simeon (1992) es posible analizar la relación entre música e imagen de acuerdo a 3 niveles de equivalencia entre ambos componentes del lenguaje fílmico:

(i) La correspondencia kinética se refiere a la velocidad de la música en relación a la velocidad de la acción. Este acuerdo a veces se logra a través del ajuste en un pulso subyacente -en tal caso es la cualidad temporal de pulso la que se estaría apareando-, aunque muchas veces dicho pulso común está ausenteen cuyo caso es el atributo de ritmo el que resulta común.

(ii) La correspondencia sintagmática se refiere al modo en el que la segmentación de la música "secunda" la segmentación del film. Simeon (1992) propone que es posible establecer una doble cadena sintagmática en la que los elementos de la segmentación cinematográfica y musical se exhiben en paralelo dejando evidente la reciprocidad y permitiendo el eventual acercamiento de lo musical a lo que se está narrando visualmente. Además, la música puede exhibir una función activa y autónoma, en la que se ubique ya no secundando, sino a la par de lo visual coadyuvando a la producción de significado. En este caso es el atributo de duración (de los segmentos de las cadenas sintagmáticas) el que se pone en juego.

(iii) La correspondencia de contenido se refiere a alusiones directas en lo sonoro a lo que se está viendo. Esta correspondencia no necesariamente involucra aspectos de la temporalidad del discurso. Aunque en general es más problemática de establecer, ciertos aspectos del contenido se pueden identificar fácilmente. Por ejemplo, una correspondencia de contenido trivial tiene lugar cuando en un video clip, se observa a los ejecutantes tocando lo que se está escuchando. Sin embargo es posible establecer correspondencia a niveles más sutiles. Por ejemplo, cuando la acción se detiene como parte del contenido narrativo y la música se interrumpe. Si bien en este caso, también se ponen en juego niveles de correspondencia kinética y sintagmática, es el contenido narrativo en sí de la interrupción, como evento, lo que se está vinculando.

Este experimento se propone explorar estos niveles de correspondencia en vinculación a al estudio de la ejecución musical expresiva. Se asume que los diversos niveles de correspondencia generan marcas en el discurso cinematográfico, enfatizando ciertos aspectos de la estructura musical, y dando lugar a una experiencia temporal particular. De manera análoga, una experiencia temporal propia emerge cuando los atributos de la microestructura expresiva (timing, dinámicas, articulaciones, etcétera) actúan como esas marcas atencionales. Se hipotetiza, entonces, que la experiencia temporal suscitada por el discurso cinematográfico particularmente afectado por los diversos niveles de correspondencia 
imagen-sonido puede ser transferida a la experiencia temporal suscitada por las marcas instiladas por la microestructura expresiva.

Para demostrarlo, se desarrolló un experimento basado en juicios de similitud. Juzgar la similitud consiste en cotejar -aun de manera no concientelos rasgos comunes y diferentes de los estímulos. Sin embargo, dos estímulos son considerados similares no simplemente porque comparten características comunes sino más bien porque sus rasgos comunes son puestos de igual modo en relevancia. (Jameson y Gentner, 2003).

En este experimento se testeó la similitud entre estímulos musicales exclusivamente auditivos y estímulos audiovisuales. Se especuló acerca del modo en el que el componente visual de estos últimos suscita una experiencia particular del tiempo que equivale a la experiencia suscitada solamente por algunos de los primeros. Cuanto más análoga sea la experiencia temporal suscitada por el estímulo audiovisual respecto de la correspondiente al estímulo enteramente auditivo, serán juzgados como más similares. Esa analogía puede dar cuenta de la transferencia de la experiencia visual a la experiencia suscitada por la microestructura expresiva. En ese sentido, la microestructura expresiva per se aportaría información relativa para el significado de la experiencia que, en el discurso cinematográfico estaría brindando la información visual.

\section{La composición}

La composición tomada como material es la Primera Balada en Sol menor, op. 23 de Chopin (Figura 1), compuesta en 1835 (Samson, 1992). Un análisis pormenorizado de esta pieza excede ampliamente el alcance de este trabajo (véanse por ejemplo los análisis de Björling, 2002; Klein, 2004; Rothstein, 1995; Samsom, 1992; Tarasti, 1994). La Balada es un tipo de composición de origen popular que tiene un sentido épico, con un claro formato narrativo (Björling, 2002), sobre una serie de repeticiones de un refrán.

Las baladas de Chopin son consideradas un género experimental en el que se combinan atributos de estilos más libres (por ejemplo la pieza de carácter) con composiciones más estructuradas (por ejemplo el vals). Debido a que el experimento realizado utilizó solamente el comienzo de la composición, se analizan aquí solamente los primeros compases.

La figura 1 exhibe los primeros 40 compases de la obra. Aunque comienza con un metro binario, el metro ternario, usado por Chopin en todas las baladas, aparece luego de la introducción. Así, el comienzo en metro binario, con un tempo tan lento, está claramente señalando el fragmento como introducción, dejando en claro que la balada propiamente dicha comienza con la aparición del refrán hacia el compás 8.

A partir del do inicial que actúa como llamada esta introducción recitativo manifiesta la influencia del estilo operístico italiano (Klein, 2004; Rothstein, 1995), sugiriendo una ejecución temporalmente libre. Este Largo se divide claramente en tres segmentos señalados por dos pausas importantes, cambios en la conducta melódica y cambios en la función armónico-tonal con implicancias en el tratamiento de la textura. A pesar de la aparente claridad con la que comienza, la ambigüedad caracterizará a toda la composición. El primer segmento plantea la ambigüedad tonal entre la tonalidad de la bemol mayor que se esboza por el arpegio del comienzo, y la de sol menor (la tonalidad real de la composición) insinuada a penas a partir de la aparición de un fa \# hacia el compás 3. El segundo segmento, resuelve la ambigüedad dirigiendo la tensión hacia sol menor (con las notas $f a$ \# y re). La llegada al re del compás 5 indica definitivamente que la tónica es sol, de modo que el silencio mucho más extenso que lo sigue (compases 5 y 6), 
FIGURA 1

Balada en Sol menor Op. 23 de Chopin (cc 1-40)
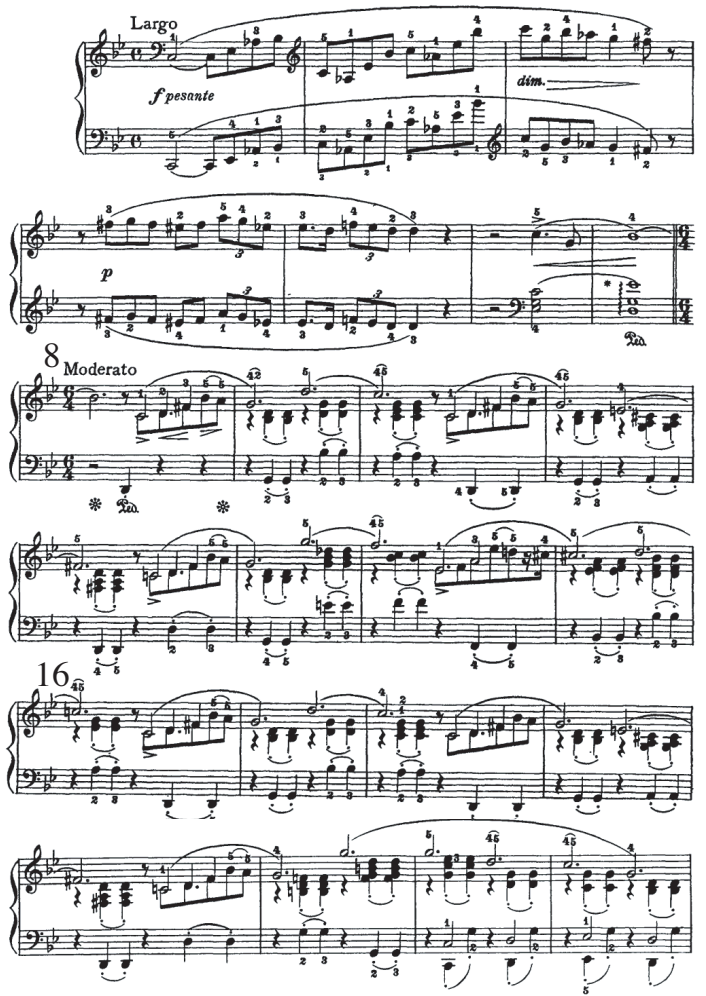

24.
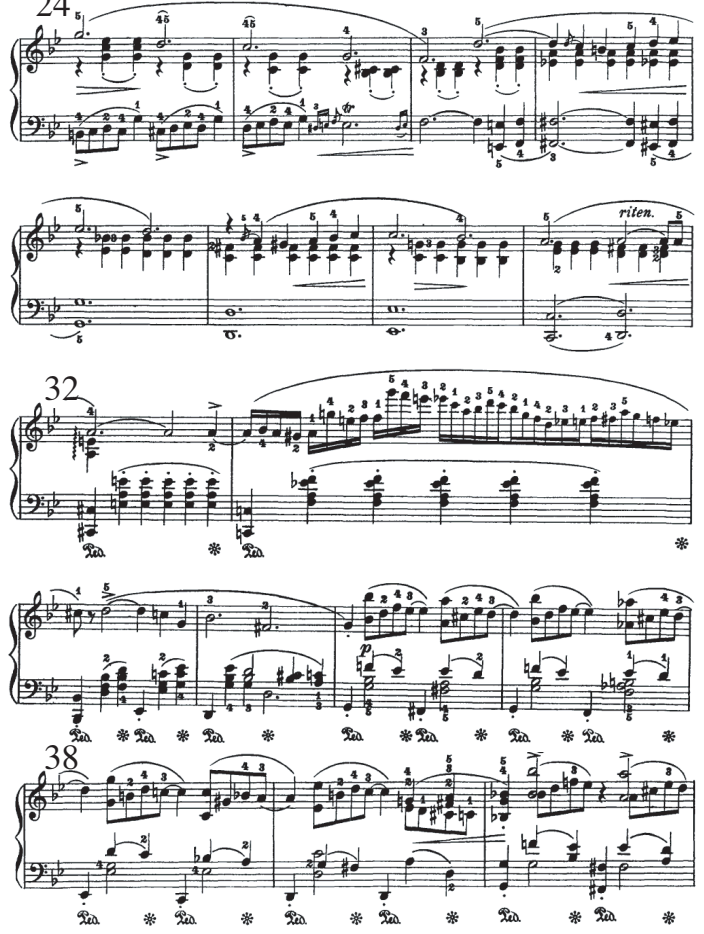
tiene un carácter decidido. El tercer segmento introduce un cambio notable de textura para afianzar con la cadencia perfecta la tonalidad real. Es notable cómo Chopin extiende esta cadencia a lo largo de 4 compases y la utiliza para encabalgar armónicamente el comienzo del Moderato (que implica el comienzo del tema del refrán de la balada). En esta cadencia, el acorde que genera la mayor tensión (compás 8) es sostenido durante 7 tiempos (el valor más largo aparecido hasta el momento).

En el compás 8, con el Moderato, comienza la Balada propiamente dicha presentando el refrán, característico en el género. De acuerdo a este refrán es posible establecer la segmentación del fragmento tal como aparece esbozado en la figura 2. Como se ve, los refranes se organizan en cuartetas, conformando la estrofa. Asimismo, es posible identificar un nivel intermedio de agrupamiento cada dos refranes, que también responde al agrupamiento del texto poético en las composiciones folklóricas de este tipo.

FigURA 2

Segmentación de la melodía de la Balada en Sol menor Op. 23 de Chopin (cc 8-21) de acuerdo a la estructura de refranes y estrofas. Cada arco pequeño es un refrán. Las llaves verticales encierran las estrofas y los arcos grandes los grupos de dos refranes (nivel intermedio). Se observa que la segunda estrofa no se completa. (Para ganar claridad se eliminaron las indicaciones de expresión y dobles plicas)

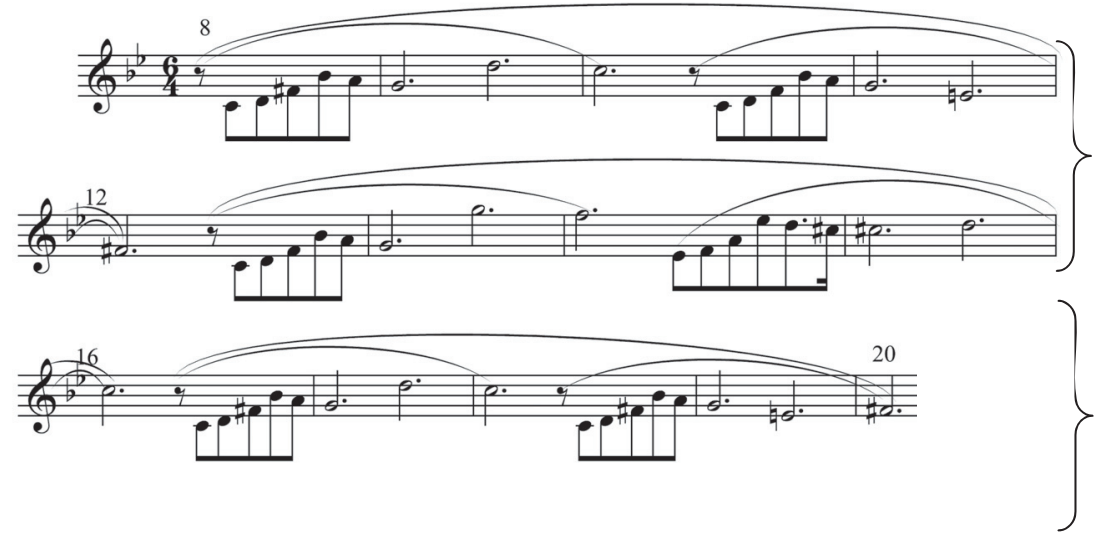

A medida que la obra progresa la claridad formal se desdibuja: la ausencia de palabras obliga a Chopin a romper prontamente la reiteración de la estrofa (Björling, 2002). Así, la segunda estrofa no se completa (compás 22). A partir de ahí, la ambigüedad aumenta por la aparición simultánea de criterios de segmentación y fraseo. La reiteración melódica será manejada en adelante como un recurso que en vez de organizar el discurso de acuerdo a un arquetipo estrófico, contribuirá de manera finamente elaborada al exaltar la ambigüedad. A partir del compás 21 , una serie de encabalgamientos entre las frases hacen más ambiguo el planteo formal. Esta ambigüedad (cuya descripción detallada excede el alcance de este artículo) genera una suerte de tensión estructural que se resuelve recién en la cadencia perfecta del compás 36. Esta cadencia es extensamente preparada a través de la definitiva disolución temática que deviene en la cadenza (pasaje de despliegue virtuosístico) del compás 33. Este pasaje "reconquista" el espacio de amplio registro explorado con precaución en la introducción, pero ahora haciendo alarde del dominio técnico-instrumental. Finalmente, todas las ambigüedades (métricas, armónicas, formales, etcétera) se resuelven en la cadencia del com- 
pás 36 donde claramente finaliza toda la sección y se arriba rotundamente a la tónica. A partir de ahí, el compás 36 introduce una nueva elaboración del tema.

En resumen este análisis morfológico clásico de la estructura de la Balada en Sol menor nos habla de una introducción segmentada en tres unidades, una estrofa completa y otra incompleta de cuatro versos que entran en contradicción con el contenido armónico de superficie, y luego una zona de mayor ambigüedad formal hasta que una cadenza deja en claro que se aproxima el fin de la sección y se resuelven todas las ambigüedades hacia el compás 36.

Sin embargo, otras perspectivas de análisis musical pueden dar cuenta de otras configuraciones en la composición. Las teorías prolongacionales de la música tonal (Lerdahl, 2001; Lerdahl y Jackendoff, 1983; Schenker, 1935, etcétera) identifican diferencias en la importancia estructural que tiene cada nota de la composición. Estas teorías postulan, por ejemplo, que en el transcurso de una melodía tonal algunas notas aparecen como más estructurales y otras cumplen la función de ornamentar o prolongar esas notas más estructurales (ver Martínez en este volumen). Por ejemplo, en el compás 4 de la Balada (Figura 1) la nota estructural es el re. El mi con el que comienza el compás, así como el movimiento re-fa-mi-re, constituyen elaboraciones de ese re. De este modo, el re es considerado una nota estructural que subyace a todo el compás 4. Ese re se conecta directamente con el do del compás 5 , que a su vez se conecta con el si bemol del compás 6, ya que el sol que lo antecede en el compás 5, es una nota más superficial, del mismo estatus estructural que el fa y el mi del compás 4. Así, subyace a la melodía de los compases 4 a 6, la progresión re-do-si bemol. A esto se lo conoce como conducción vocal subyacente. En general, el movimiento melódico que aparece en la superficie de la composición tiende a simplificarse en los niveles subyacentes, donde se configuran las progresiones lineales. La figura 3.a muestra la progresión lineal que subyace los compases 4 a 8. De acuerdo a Schenker (1935) es esta sólida organización subyacente la que brinda a la composición el sentido de coherencia tonal más allá de todas las fluctuaciones que puede presentar en la superficie. La figura 3 muestra la secuencia de progresiones lineales que subyacen a la superficie entre los compases 4 y 21. Es importante notar que la estructura prolongacional se organiza a partir de los componentes armónico y melódico de la música, dejando fuera de consideración los componentes rítmico y métrico. Por esta razón, por ejemplo, progresiones lineales similares, presentan distinta ubicación respecto de los compases, o notas que presentan valores rítmicos muy breves (como el la del compás 8) pueden tener un importante estatus estructural y formar parte de la progresión lineal.

La figura 3 también permite ver como la sucesión de progresiones lineales (rasgo de la conducción vocal subyacente) contradice o se encabalga con la sucesión de refranes (rasgo de la superficie musical, señalado por las barras verticales - las dobles barras indican el nivel de la estrofa, las barras punteadas el nivel del verso, y las barras simples el nivel de los dos versos). De acuerdo a la perspectiva de conducción vocal subyacente el RE de compás 4 resulta crucial. La primera progresión lineal unifica el pasaje del Largo al Moderato, que en la superficie se exhibía fragmentado y ambiguo. También el salto de octava sol-sol del compás 13 divide la prolongación de la segunda progresión lineal de la prolongación de la tercera progresión. De este modo las progresiones lineales están organizando la segmentación en un nivel más profundo.

\section{Una performance cinematográfica}

En el film El Pianista, Roman Polansky (2002) utiliza la Balada en Sol menor de Chopin para una escena clave. En ella se define la suerte del protagonista sin- 
FIGURA 3

Análisis de la Conducción Vocal Subyacente de la melodía de la Balada en Sol menor Op. 23 de Chopin (cc 4-21) de acuerdo a las Progresiones Lineales - los números sobre las notas indican los números de los compases en los que aparecen esas notas. Obsérvese que las progresiones comienzan en la 5 ta. de la escala (nota re) y finalizan en el sol. Las progresiones lineales a y c despliegan sendas prolongaciones de tipo "prefijo" (antes de la primera nota re). Las b y d muestran prolongaciones "subfijo" (luego de la última nota sol)
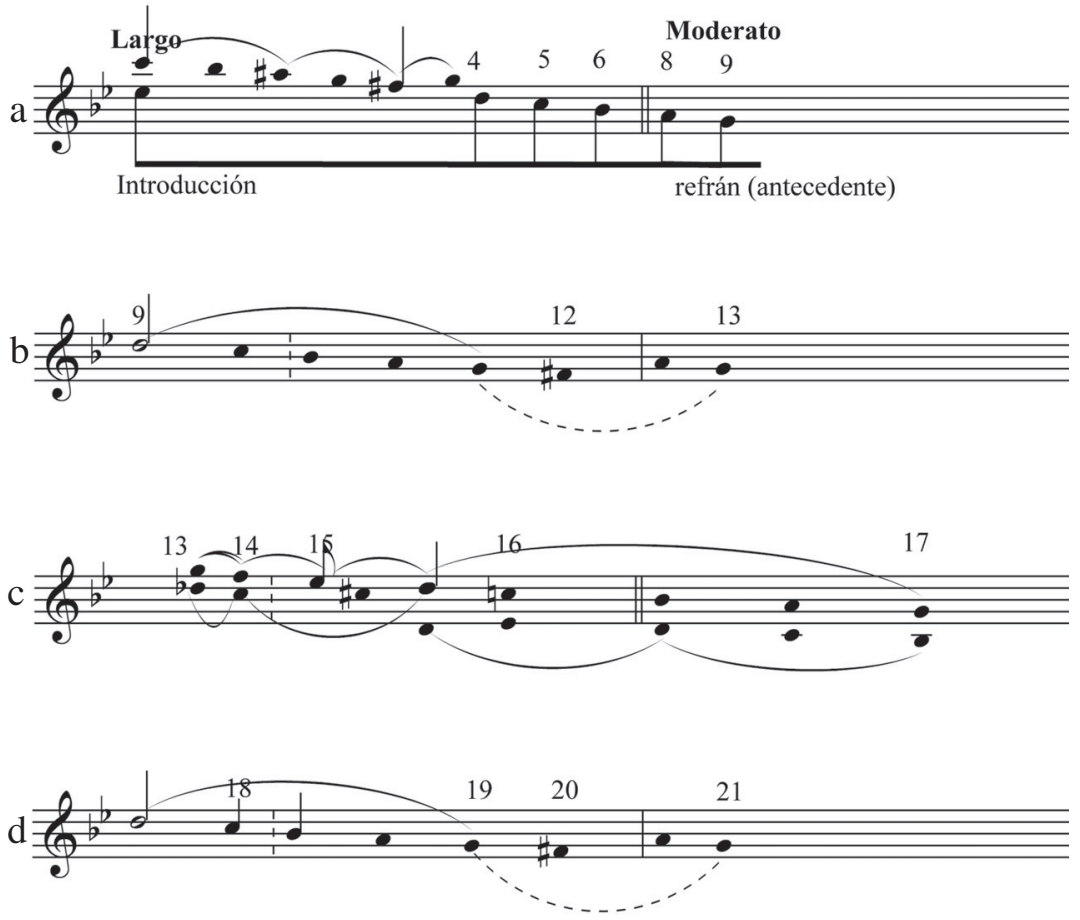

tetizando el contenido del film en cuanto a la relación entre la música y la vida (o más bien, la supervivencia), la oposición entre arte y destrucción y la caducidad de ciertas relaciones de poder. Además a lo largo de la escena se percibe una profunda transformación psicológica de ambos personajes.

Se puede describir la escena en términos de las relaciones de correspondencia entre imagen y música mencionadas (Simeon, 1992). En cuanto a la correspondencia cinética se destaca un tempo global de la escena notablemente lento por el escaso movimiento que presenta: una extensísima única toma, que sirve de introducción a la introducción de la composición, revela el lento andar de ambos personajes hacia el piano que antecede al lento transcurrir de la introducción Largo. Luego, cuando comienza el Moderato, podría decirse que la imagen es más lenta que la música:.tiene lugar también un lento andar del personaje del capitán desde el piano hasta una silla alejada en la sala. Sin embargo, en relación a la toma anterior (mucho más estática) ésta presenta un tempo (que al igual que en la música) es relativamente más rápido, aunque todavía muy lento. Para el establecimiento de relaciones cinéticas son importantes y significativos los movimientos de la ejecución, tanto los sutiles gestos corporales, como los ágiles movimientos de las manos sobre el teclado. En los pasajes musicales veloces el movimiento de las manos es el único posible para establecer correspondencia cinética. En efecto, Polansky enfatiza esa correspondencia en los pasajes virtuosísticos como el tipo cadenza del compás 33, o el trino de la mano izquierda del 
compás 25, en los que el tempo de lo que se escucha es rápido, al igual que el movimiento de lo que se ve (las manos del pianista).

$\mathrm{El}$ análisis de la correspondencia sintagmática permite apreciar la interpretación estructural de la composición implicada en la realización de la escena. Por ejemplo, luego de la cadencia del compás 36, cuando se escucha la elaboración temática (que en el contexto de uniformidad de lo escuchado hasta ahí, aparece como algo nuevo) se observa por primera vez, en una escena que lleva más de 9 minutos completamente en interiores, una imagen exterior. Así aparece lo nuevo, el afuera.

No obstante, en el comienzo de la pieza se puede ver lo más interesante de la correspondencia sintagmática (Figura 4). En primer término, la primera toma comienza 1 minuto 25 segundos antes del comienzo de la ejecución del pianista. Es una extensísima toma que se vincula al extenso arpegio del comienzo, como si la música existiera de antes y solamente a partir del do grave comenzara a hacerse audible. La siguiente toma (el plano del capitán) se articula en el re del compás 5 (la primera nota de la progresión lineal, véase Figura 3) y atraviesa los extensos silencio, el cambio de tempo (al Moderato) como lo hace la primera progresión lineal. Si los puntos de montaje funcionan como acentos fenoménicos que capturan la atención del espectador (Boltz, 1992), entonces el re está siendo enfatizado por el sintagma visual. La toma finaliza en el compás 13 en el momento del salto de octava que separa la segunda de la tercera progresión lineal (ver Figura 3). De este modo, este sintagma refuerza la progresión lineal (Figura 4). En otros términos, el montaje de la escena pone de relieve la interpretación de conducción vocal subyacente. Sin embargo, los movimientos dentro de la toma del capitán capturan la estructura de superficie del pasaje (Figura 2): en el momento en el que comienza el refrán en el compás 8 comienza el giro del capitán (es el primer movimiento ostensible que realiza). Durante todo el primer refrán el capitán se traslada hasta la silla, durante el segundo refrán gira lentamente y se sienta, llegando a sentarse en el comienzo del tercer refrán. Por lo tanto la toma tiene 4 partes: (i) rostro fijo, (ii) giro y traslado, (iii) giro y sentada, (iv) (más breve) sentado fijo. En la figura 4 se observa esta correspondencia sobre el gráfico de conducción vocal subyacente y se señala la relación jerárquica que en lo visual representa el nivel de la toma y el nivel del movimiento del personaje.

FIGURA 4

Correspondencia sintagmática entre la imagen y la música (en la partitura el análisis de la conducción vocal subyacente)
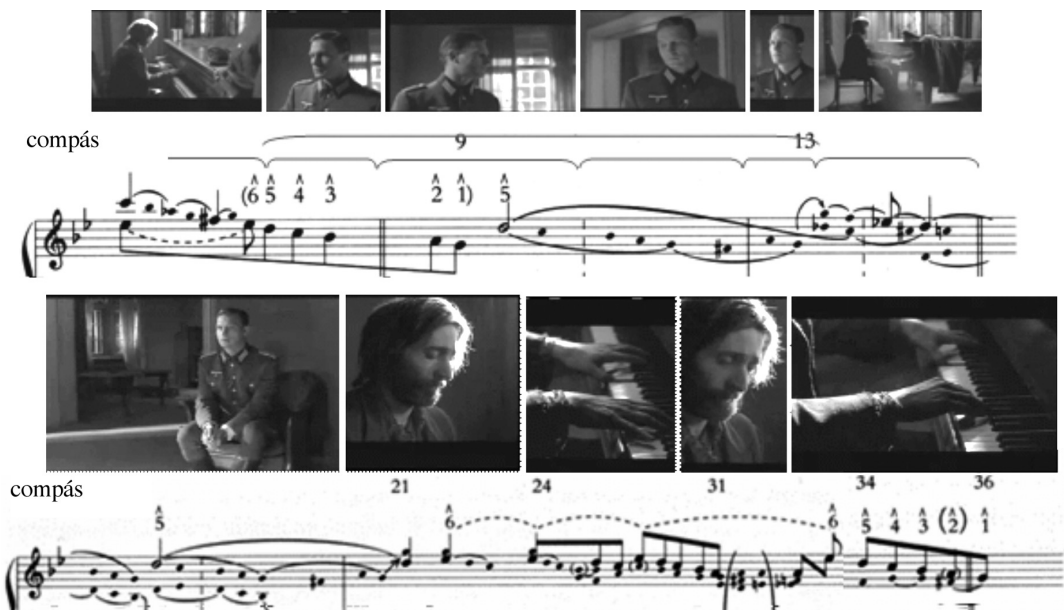
La siguiente toma -Hosenfeld sentado- abarca la primera mitad de la segunda estrofa, ajustándose a la articulación formal de superficie en la composición (Figura 2). A partir de ahí, al desaparecer el refrán con sus progresiones lineales, resultando cada vez más ambigua la segmentación musical, Polansky abandona la correspondencia sintagmática y profundiza la correspondencia de contenido, en la relación entre los gestos dolientes del rostro del pianista y ciertos giros melódicos (en particular de notas repetidas). Sin embargo, este nivel de correspondencia se muestra más claramente en el comienzo del Largo. Aquí la incertidumbre es el contenido del primer silencio. El movimiento de recoger los dedos que hace el pianista en ese silencio siembra un duda que excede el hecho de si podrá en efecto tocar y plantea si podrá sobrevivir. Así, se instala una clara correspondencia entre la incertidumbre tonal (discutida arriba) y la planteada por la narración. Al arribar al re que inicia la primera progresión lineal, el gesto y la actitud de Hosenfeld indican, en conjunción con la estructura tonal, la disipación de la incertidumbre y se vislumbra que la ejecución va a continuar. Finalmente la nota larga del compás 7 que da lugar al arranque de la balada propiamente dicha, pone en movimiento (de retirada) al personaje del capitán nazi.

En resumen, el componente visual está utilizado en la escena de manera análoga a cómo la microestructura expresiva es utilizada en una performance exclusivamente instrumental: los recursos expresivos de esta escena están organizados alrededor de una idea particular de la estructura musical que se combina con otros aspectos narrativos propio del relato del film. El timing visual es uno de los medios expresivos más poderosos del lenguaje cinematográfico, y por lo tanto resulta definitivo en la comunicación de la atmósfera emocional. La temporalidad de los recursos visuales se vincula con la temporalidad de ciertos aspectos de la estructura musical a través de las tres categorías de correspondencias y puede caracterizarse sucintamente por: (i) una segmentación parsimoniosa especialmente en la primera parte de la ejecución; (ii) un montaje que inicialmente se ajusta a los fenómenos de niveles subyacentes (progresiones lineales), (iii) sutiles movimientos de un personaje que reflejan en una toma la organización de la superficie musical (refranes); (iv) movimientos relativamente lentos excepto en ciertos puntos clave del discurso musical en el que los movimientos son muy rápidos (manos).

Es posible, suponer entonces, que la ejecución pianística que mejor proyecte esos mismos aspectos temporales de la estructura musical dará lugar a una experiencia temporal análoga, reforzando la similitud entre los estímulos.

\section{Las performances pianísticas}

Se tomaron 5 ejecuciones de la Balada de Chopin, entre las cuales figura la que grabó Janusz Olejnizack (2002) para la banda de sonido del film de Polansky. Las otras 4 fueron las de Alfred Cortot (1933), Vladimir Horowitz (1968), István Székely (1987) y Evgeny Kissin (1999). Se analizó la regulación temporal de cada una de las ejecuciones (para una reseña de la metodología de análisis véase Repp 1992, 1998).

Los 5 artistas utilizaron estrategias globales de tempi diferentes. La tabla I exhibe los valores de tempo para la primera estrofa (compases 8-16) y para el pasaje virtusístico del compás 33. Se observa que Kissin es el pianista que más aumenta la velocidad en el compás 33, figurando mayor virtuosismo. Las diferencias entre las diferentes estrategias podrían estar dando cuenta de concepciones distintas de este comienzo, según las cuales algunos artistas (lo que abordan la estrofa más rápido) estarían suponiendo un carácter más de salón al vals del comienzo, mientras que los otros estarían explotando más sus rasgos dramáticos. 
TABLA I

Valores de tempi (en negras por minuto) para las 5 ejecuciones en la primera estrofa y en el compás 33. La columna de la derecha muestra la variación en el tempo del 33 respecto del tempo inicial

\begin{tabular}{llll}
\hline Artista & Compases 8-16 & Compás 33 & Variación en \% \\
Cortot & 110 & 93 & -15.3 \\
Horowitz & 105 & 90 & -13.8 \\
Kissin & 90 & 96 & 7.1 \\
Olejniczak & 102 & 109 & 6.7 \\
Szèkely & 121 & 102 & -15.3 \\
\hline
\end{tabular}

Por razones de espacio solamente se describen aquí aquellos datos del análisis que resultan relevantes para comparar las ejecuciones de Olejniczak y Kissin, que, tal como se verá más adelante, son la que resultan de interés para el experimento presentado. En los compases iniciales, el timing de Kissin es el que presenta mayor variabilidad. Su estrategia consiste en señalar el final de los refranes teniendo en cuenta la jerarquía de cada uno de ellos. De este modo, el segundo refrán presenta un final más alargado que el primero, pero menos retenido que el cuarto. Por su parte, Olejniczak también alarga considerablemente el final del cuarto refrán como remarcando el final de la estrofa. Al mismo tiempo, Kissin es el que presenta la transición del 3er. al 4to refrán de manera más unificada (sin realizar rallentando entre ambos). De este modo unifica ambos refranes, tal como lo sugieren las progresiones lineales (véase Figura 3).

Kissin es el único en separar claramente, con un importante alargamiento, la estructura estrófica de la región más ambigua que se abre a partir del compás 21 . Sin embargo, Olejniczak señala con gran dramatismo este punto alargando el sOL del compás 22.

En el pasaje de la secuencia melódica del compás 26 y ss. Kissin acelera el tempo en general enfatizando además los picos del contorno melódico de ambas unidades con alargamientos relativos del mi bemol del compás 28, y del DO del compás 30. Luego, el acorde arpegiado del compás 32 es notablemente retenido en todas las ejecuciones excepto en la de Kissin, que lo toca más a tempo. Este incremento en el tempo y la homogeneidad de la regulación temporal caracteriza la ejecución de Kissin principalmente en los pasajes veloces, el trino de la mano izquierda en el compás 25 y la cadenza del compás 33, brindando una apariencia general de marcado movimiento y virtuosismo.

En una inspección un poco más pormenorizada se pueden apreciar algunos detalles por demás relevantes. En el análisis llamó la atención un alargamiento en el último tiempo del compás 8 en la ejecución de Kissin. Se trata de un comportamiento altamente idiosincrásico siendo que no solamente es el único pianista que lo realiza sino que también lo repite en las sucesivas reiteraciones del motivo del refrán. Para examinar esto más de cerca, se realizaron los perfiles temporales tomando esta vez cada nota de la melodía en vez de medirlos por negra. En la figura 5, cuyo gráfico compara las ejecuciones de Kissin y Olejniczak, se aprecia claramente el modo en el que Kissin alarga sistemáticamente los la. Esta nota es la que pone de manifiesto el conflicto entre la segmentación de superficie y la que obedece a las progresiones lineales. A nivel de la superficie musical el la es una nota que ocupa una posición métrica muy débil y además es de las más breves de todo el pasaje, por lo tanto, tiende a "pasar desapercibida". Sin embargo en un nivel subyacente más profundo, es una nota clave tanto para completar las progresiones lineales como para configurar la prolongación de la tónica. Además, aunque la primera nota del Moderato queda relativamente alargada, es el pianista que menos estira el tempo en ese punto. De este modo, la primera pro- 
gresión lineal y el pasaje del Largo al Moderato quedan notablemente unificados. Con este pequeño detalle, Kissin pone de relevancia las progresiones lineales. Notablemente, cuando la estructura se hace más ambigua (compás 21) tiende a homogeneizar el rubato y no lo ciñe a ninguna pauta de la conducción subyacente.

Es posible decir entonces que, como Polansky en el film, Kissin organiza el timing de su ejecución de acuerdo a la conducción vocal subyacente. Desde este punto de vista (en cuanto a la relación que sostienen con la estructura musical), la organización temporal de ambas performances (Kissin y Polansky) son análogas. Del mismo modo, la progresiva aceleración de la ejecución de Kissin hacia el compás 33 y la homogeneidad con la que ejecuta los pasajes virtuosísticos (el trino y la cadenza) hace que sea la ejecución con mayor movimiento relativo en dichos puntos. Vale recordar que Polansky en ese punto activa el movimiento por correspondencia cinética al mostrar las manos del pianista.

\section{FigURA 5}

Perfiles de timing de las ejecuciones de Olejniczak y Kissin (cc-8-17) por nota de la melodía. Arriba detalle de la conducción vocal subyacente (las dos primeras progresiones lineales y el comienzo de la tercera, cc. 1-16). Más arriba, detalle de la superficie musical (mano derecha, cc. 8-11)

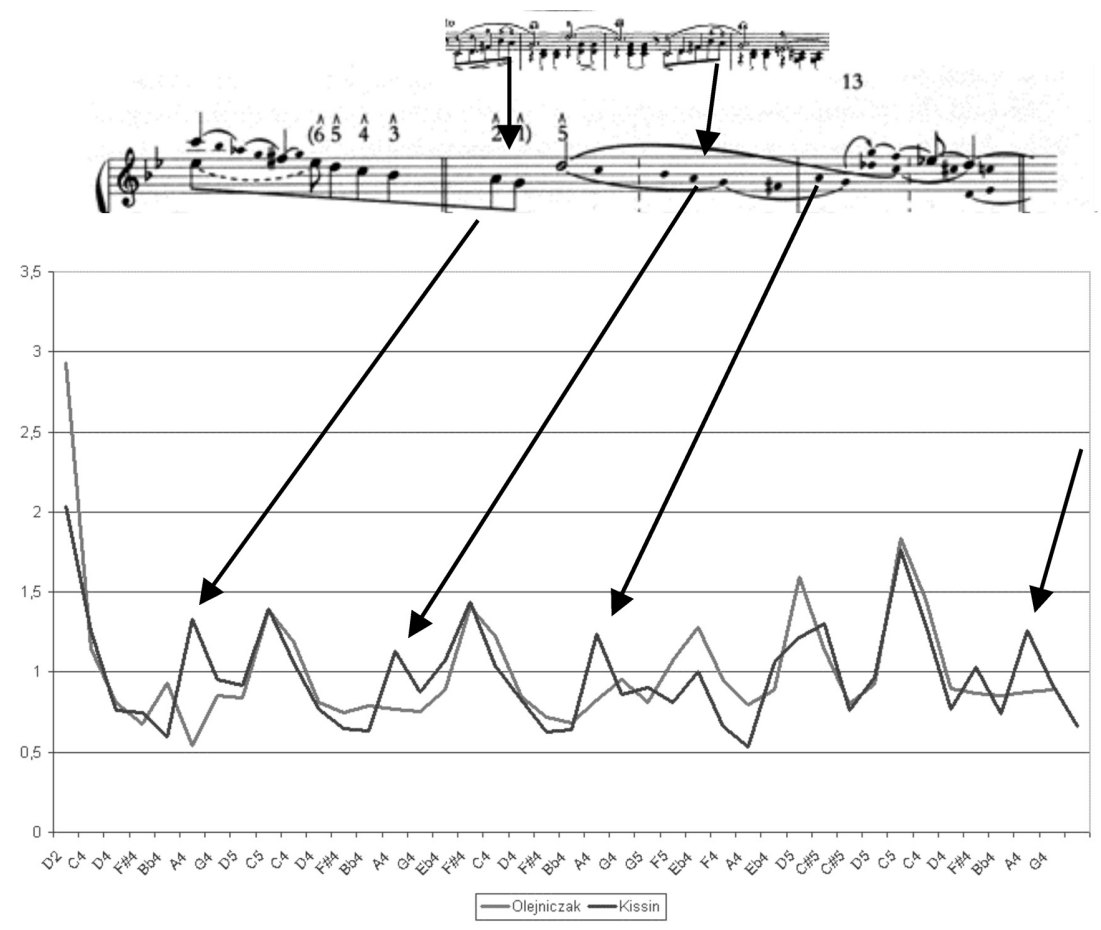

\section{MÉTODO}

\section{Sujetos}

Ciento veinticinco estudiantes universitarios tomaron parte en el experimento (edad media: 24,8 años), 42 mujeres y 87 varones. Todos los sujetos tenían al menos 1 año de entrenamiento musical sistemático. La media de estudio musical fue de 6,1 años. Se tomó ese valor para dividirlos en dos grupos de acuerdo a la experiencia musical sistemática: moderada experiencia, de 1 a 6 años $(N=84)$ y avanzada experiencia $(N=41)$ más de 6 años. Los sujetos se repartieron al azar en 
las dos condiciones experimentales. Por razones operativas ambas condiciones tuvieron diferente número de sujetos. La condición experimental incluyó a 77 sujetos y la condición control a 48 .

\section{Estímulos}

\section{Los estímulos audiovisuales}

La extensa escena del encuentro del film The Pianist de Roman Polansky (2002) (desde 112 minutos del comienzo del film hasta el momento en el que la ejecución llega al compás 40 de la composición, punto en el que la ejecución de la escena se eslabona con la coda final (compás 209), salteando todos los compases entremedio) fue utilizada como estímulo audiovisual para la condición experimental. De este modo, además de la ejecución de la Balada de Chopin, el estímulo muestra algunos momentos importantes en la narrativa de la escena con el objeto de contextualizar dramáticamente la ejecución de la pieza. Este estímulo constituyó el video clip experimental.

Para la condición de control se elaboró un video clip control utilizando una serie de imágenes neutras de espacios vacíos con puertas abiertas, a los cuales la cámara entraba y salía mediante un lento travelling. Se consideró que estas imágenes no aportaban ningún sentido narrativo que pudiera identificarse con el film del grupo experimental. Además el montaje no coincidió con ningún punto estructural observado en la partitura, y el movimiento de la cámara era lento y constante. De esta manera se trató de evitar todo tipo de correspondencia sintagmática, cinética y de contenido con la obra musical. Se le adosó a dichas imágenes la banda sonora de la escena utilizada en la condición experimental. Así, en ambas condiciones experimentales se escuchaba la misma ejecución de la Balada en sol menor de Chopin pero se veían diferentes imágenes.

\section{Los estímulos auditivos}

Se tomaron las 5 ejecuciones de la Balada en sol menor de Chopin analizadas. Debido a que la introducción -Largo- en la ejecución del film corresponde a la grabación de Olejniczak se tomaron los fragmentos comenzando en el compás 3 (fade in durante todo el compás) hasta el compás 40 (fade out de 40.1 y 40.3).

\section{Aparatos}

Los estímulos audiovisuales fueron proyectados utilizando una computadora con un proyector data show sobre una pantalla blanca. La proyección fue de tamaño variable (según la disponibilidad de distancia proyector-pantalla en cada caso) pero siempre fue suficientemente amplia (estilo cinema). Los clips de audio fueron grabados en un $\mathrm{CD}$ y reproducidos en un equipo estéreo. Las condiciones fueron similares para todos los grupos.

\section{Procedimiento}

Los sujetos observaban en primer lugar el video clip completo sin recibir instrucciones específicas. En el caso de la condición experimental se les contó a los sujetos un resumen del argumento hasta el momento de la escena vista con el objeto de contextualizar la observación y procurar que se involucraran en la atmósfera emocional del film. A continuación escuchaban los cinco clips de sonido. Los sujetos tenían que juzgar en una planilla, utilizando una escala de nueve puntos la similitud entre la ejecución escuchada en cada estímulo auditivo y la ejecución (recordada) del estímulo audiovisual. En ambas condiciones los sujetos 
desconocían el procedimiento al momento del ver el estímulo audiovisual, es decir que no sabían que deberían comparar la ejecución, para evitar que atendieran exclusivamente a las cuestiones de ejecución soslayando el aspecto visual. En todos los casos los sujetos sabían que la tarea se vinculaba a una investigación en ejecución musical.

\section{Diseño}

El diseño de la investigación constó de dos condiciones diferentes. En la condición experimental los sujetos veían el video clip experimental y luego realizaban los juicios de similitud escuchando los 5 estímulos auditivos. En la condición control, el video clip experimental era reemplazado por el video clip control. La prueba se desarrolló en pequeños grupos (de 8-10 personas por grupo) que escucharon los 5 clips de sonido en diferentes órdenes aleatorizados.

\section{RESULTADOS}

Se realizó una análisis de varianza de mediciones repetidas con la variable Artista como factor intra sujetos y las variables Condición, Instrumento, Experiencia Musical y Género, como factores entre sujetos. Los resultados se observan en el gráfico de la figura 6. Los factores género, experiencia e instrumento no resultaron significativos, de este modo no se hallaron diferencias en las respuestas respecto de estas variables.

FiguRA 6

Juicios de similitud entre los video clips y los estimulos de sonidopara la condición experimental (derecha) y la condición control (izquierda)
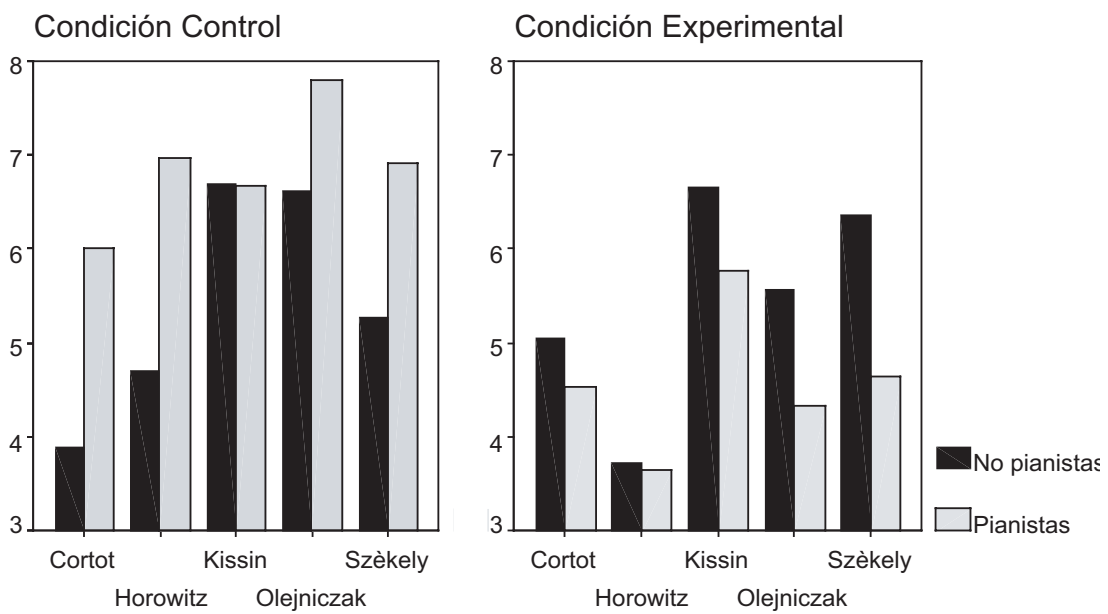

Los gráficos muestran las medias de los juicios de similitud para ambas condiciones. El factor Artista resultó significativo $\left(F_{[121-4]}=3,535 p<.007\right)$. También el factor Condición resultó significativo $\left(F_{[124-1]}=19,293 p<.000\right)$, revelando que los sujetos en la condición control tendieron a considerar más similares las ejecuciones de los estímulos de sonido (en su conjunto) a la de los video clips. Se puede pensar entonces que el contexto del film brinda al oyente una cantidad de factores que diferencian la experiencia de audición a partir del film y a partir de los clips de sonido más que el contexto del video abstracto utilizado como control. Sin embargo, esta puede ser una observación apresurada si no se tiene en 
cuenta que la interacción entre los factores Condición e Instrumento arrojó una significación marginal $\left(F_{[121-2]}=4,699 p=.032\right)$. En los gráficos se aprecia que fueron los sujetos pianistas los que más variaron sus juicios de similitud entre la condición experimental y la condición control. Es decir que parecería que las condiciones del film (narrativa, montaje, etcétera) que no aparecen en el video abstracto afectaran más a los sujetos pianistas que a los no pianistas.

Más relevante a los objetivos de la investigación es la interacción entre los factores Condición y Artista que también arrojó una significación marginal $\left(F_{[118-6]}=\right.$ $2,674 p=.032$ ). Esto implica que los juicios de similitud fueron diferentes en la condición experimental que en la condición control. Se ve claramente que en la condición control, la ejecución que los sujetos estimaron más similar a la del video clip fue la Olejniczak, que en efecto era la utilizada en el video. Por el contrario, los sujetos en la condición experimental consideraron más similar a la ejecución del video la de Kissin y la de Szèkely que la del propio Olejniczak. Un contraste post-hoc reveló que solamente los juicios de similitud para la ejecución de Kissin resultaron significativamente diferentes de los juicios para la ejecución de Olejniczak $\left(F_{[1-75]}=6,754 p=.01\right)$. En otras palabras, los sujetos que vieron la escena del film consideraron más similar a lo que escucharon durante esa experiencia la ejecución de Kissin que la ejecución que en efecto escucharon durante la experiencia, la de Olejniczak.

\section{DISCUSIÓN}

Vimos aquí los extraños resultados de un experimento en el que surge una ilusión: una ejecución musical, la de Januz Olejniczak, se parece más a otra, la de Evgeny Kissin, que a sí misma. Por supuesto, los rasgos del estímulo audiovisual que los sujetos compararon exceden a los de la ejecución musical aislada, incluyendo no solamente cualidades visuales del estímulo sino también propiedades narrativas. Sin embargo, lo enigmático es que otra ejecución sí pudiera suscitar una experiencia similar a partir de sus particularidades expresivas. Aunque este tema está recién abierto a la investigación, se pueden esbozar algunas conjeturas.

Sabemos que en la temprana infancia la modalidad de la estimulación es menos importante que la organización temporal (Lewkowicz, 1992), ya que los fenómenos temporales parecen procesarse independientemente de la modalidad estimular (Wittman y Pöppel, 1999/2000). La estimulación sensorial es registrada por sistemas múltiples que son sensibles a las invariantes temporales (Lewcowicz y Kraebel, 2004), en particular las experiencias de duración del tiempo, y de la sucesión-simultaneidad de eventos. De acuerdo con Evans (2005) la percepción del tiempo es una experiencia interna, de origen fenomenológico que se refiere principalmente a la organización del transcurrir en unidades de sentido. Así, la experiencia del tiempo va más allá de los datos perceptuales concretos. Los resultados de este estudio contribuyen en ese sentido. Permiten decir que en la recepción estética (tanto del film como de la ejecución musical), organización temporal de los rasgos expresivos se experimenta como más importante (en el recuerdo) que la modalidad y/o contenidos de los rasgos específicos que la determinan. Esa organización temporal parece ser el sostén de la significación de la experiencia tal como sugiere Imberty (1997) acudiendo a la noción de perfiles de activación de Stern (1985). Si, como ocurre en la temprana infancia, la experiencia perceptual no es recuperada a través de una representación perceptual específica, sino a través del registro del perfil de la actividad que la estimulación supone a lo largo del tiempo, entonces la experiencia musical podrá ser transmodal en la medida que el perfil de la actividad suscitada pueda despojarse de sus rasgos sonoros conservando su estructuración temporal. Pudimos advertir que esto ocu- 
rre en la infancia, durante el tercer año de vida del niño (Shifres y Español, 2004). Observando escenas de juego de ficción, identificamos diversos modos en los que la estructura temporal claramente definida del juego musical se introduce en el juego de ficción. El juego musical le brinda al infante una estructura temporal definida sobre la cual montar los significados ficcionales construidos a lo largo del juego.

Del mismo modo, la organización temporal de la ejecución de Kissin parece darles a los oyentes un soporte para construir significados no lexicales (Evans, 2005) análogos a los que el lenguaje visual y narrativo les brinda a los espectadores del film. La saliencia perceptual de los estímulos colaboraría en esta organización del transcurrir. Por ejemplo, el montaje del film favorece la saliencia de la nota re del compás 3. Por su parte, Kissin, enfatizando el la del compás 8, deja expuesta la progresión lineal subyacente y de este modo también distingue el re, al revelar su jerarquía estructural. Es decir ambos estímulos impulsan la nota re, aunque usando muy diferentes recursos. Particularmente en la ejecución de Kissin, esa nota es impulsada indirectamente, a través del conocimiento implícito de las progresiones lineales que el oyente tiene, suscitada por el énfasis sobre la nota la.

En síntesis, el fenómeno transmodal tiene lugar porque ambas estimulaciones, la visual y la microtemporal, suscitan organizaciones del transcurrir equivalentes. Sin embargo, no estamos diciendo que las regulaciones temporales de los componentes visuales y expresivos sean iguales en términos de duraciones reales. La experiencia del transcurrir en la obra musical es mucho más compleja que el timing de cualquiera de sus componentes aislado. Es el resultado de las tensiones suscitadas entre todas las organizaciones temporales experimentadas en simultaneidad.

Contrariamente a lo que la metáfora de la transmisión de la información considera, la metáfora de la danza distingue la importancia de la configuración de la obra musical como un todo temporal, más que como un todo lógico, argumental. Parafraseando a Paul Ricouer (1984) cuando se refiere a la configuración del tiempo en la narración, es posible decir que el significado emerge de la configuración del tiempo considerando a la ejecución musical expresiva, como "un conjunto de experiencias temporales que hay que compartir" (p. 536). Así, la transmodalidad robustece el lazo de mutualidad tendido entre los participantes de la ejecución como experiencia intersubjetiva. La temporalidad intersubjetiva se construye y se comparte transmodalmente. La perspectiva de segunda persona permite entender la comunicación musical sin necesidad de entrar en la discusión acerca de los referentes significativos de la música (que abundan en los debates musicológicos, $c f$. Nattiez, 1990). Desde este enfoque, los aspectos morfológicos y sintácticos del discurso musical, en tanto se organizan en el tiempo, sientan las bases de la comunicación. Una comunicación que, como en la temprana infancia, no está atravesada por la semanticidad del lenguaje y en la que no circula un conjunto de señales que demandan una respuesta sino un objeto para la contemplación (Deliège, 2000). En el caso de la música, esta contemplación adquiere la forma de lo que Nicholas Cook (1990) denomina escucha musical (orientada emocionalmente) en oposición a una escucha musicológica (orientada teóricamente). En nuestro experimento, al orientar la escucha hacia el contenido emocional del film, se buscó desamarrar a los oyentes de cualquier consideración teórica acerca de la ejecución disponiéndolos para una audición que pudiera centrarse en la intuición del tiempo. En este proceso la obra musical con todos sus rasgos estructurales y microestructurales puede ser vista como materia de la actividad imaginativa que configura el tiempo en la ejecución. La escucha musical habilita la experiencia transmodal, la musicológica, por el contrario, la inhibe. Esos materiales se procesan y almacenan de acuerdo con los significados suscita- 
dos en esa experiencia en particular, facilitando su traslado a otros modos representacionales, a menudo en términos metafóricos, atravesados por consideraciones transmodales. Esto es lo que Reybrouck (2003) denomina estrategias de semanticidad que el oyente utiliza para cargar semánticamente lo que escucha (en este caso, un conjunto de rasgos performativos, rubato, dinámica, etcétera). Las secuencias fílmicas y auditivas del experimento fueron apareadas de acuerdo a los significados asignados a través de esas estrategias de semanticidad, no de acuerdo a la afinidad de los significantes sonoros. El oyente al recordar no reconstruye la señal auditiva sino su significado. Para esto es capaz de agregar o quitar atributos. Así, es posible especular con que los atributos expresivos de la ejecución de Kissin tendieron a completar los huecos de significado que quedaron al desaparecer los atributos significantes más complejos de la secuencia fílmica.

La ejecución expresiva funda una tensión entre el tiempo estructural de los eventos en la obra -el tiempo de la estructura composicional-y el tiempo de la microestructura expresiva, que goza de una nueva lógica temporal. Por ejemplo, la partitura de la Balada en Sol menor prescribe que todos las notas del compás 2 (todas corcheas) deben ser isócronas. Sin embargo, en el tiempo real de la ejecución el ejecutante altera expresivamente esa isocronía dando lugar a una nueva lógica temporal en la ejecución provee nuevos elementos para la significación. Esto se pudo ver en la organización temporal tan particular de la ejecución de Kissin. El oyente se entrega a la experiencia dispuesto a comprender esa nueva lógica temporal.

El tiempo estructural está marcado en la experiencia del oyente por un conjunto de estructuras musicales más o menos tipificadas para un cierto lenguaje musical. Por ejemplo, en el estilo clásico se pueden preestablecer ciclos temporales a nivel de la frase musical (por ejemplo frases simétricas de 4 compases), a nivel del metro (por ejemplo la caída de un acento cada tantos impulsos), y a nivel de pulso (por ejemplo un impulso cada x tiempo, tempo negra $=60$, etcétera), entre otros. Son los tiempos de su cultura, o, siguiendo a Ricouer (1985) el tiempo de los acontecimientos (musicales) en el mundo. Los acontecimientos de la obra en la ejecución musical, por el contrario están determinados por el tiempo de su ejecución. En otros términos, el oyente contrasta el tiempo de la ejecución con el tiempo de su experiencia de vida que es el tiempo estructural. Y de esa tensión emerge el significado expresivo. En otros términos, la expresión se significa a partir del conflicto entre la configuración temporal preexistente (propia de la cultura musical de pertenencia) y la "refiguración de la experiencia temporal por este tiempo construido” (Ricouer, 1985, p. 115). De este modo, lo que adquiere significado en este tipo de experiencia musical es el conflicto temporal que introduce el rubato. Siguiendo a Ricouer esto produce tensiones de conjunción/disyunción, ajusteldesajuste, o sincroníalasincronía que proyectan el tiempo de la ejecución como un tiempo de ficción, un tiempo imaginado.

Estas tensiones solamente pueden entenderse si se considera la ejecución como una experiencia de intersubjetividad desde la perspectiva de segunda persona. Como hemos visto, este enfoque propone que la configuración del tiempo es vital en nuestro mundo emocional y comunicacional. Muchas habilidades importantes para construir ese mundo, tales como la sincronía interactiva, dependen directamente de la configuración del tiempo. De hecho estamos neurológica y psicológicamente preparados para comprender sutiles variaciones de tiempo que apartan el tiempo del mundo, el tiempo conocido, el tiempo estructurado de manera previsible, del tiempo de la experiencia en particular, el tiempo de la ejecución musical (Trevarthen, 1999/2000; Wittmann y Pöppel, 1999/2000). Esas sutiles discriminaciones entre estructuras temporales son la base de los intercambios emocionales que tienen lugar en el compartir en el transcurso del tiempo el hacer conjunto con el 
otro. Hemos sido preparados, filogenética y ontogenéticamente hablando, para significar esos contrastes temporales en términos emocionales. Esta preparación es muy simple, se vincula a una línea evolutiva en los mecanismos de regulación temporal de las conductas interactivas, que va desde un mecanismo por tiempo de reacción, según el cual actuamos como respuesta a la acción del otro, hacia mecanismos predictivos (Merker, 2002). En primer término el mecanismo por familiaridad por el cual actuamos en virtud del conocimiento previo que tenemos de patrones típicos de comportamiento del otro que nos resulta familiar, y en segundo lugar el mecanismo de pulso subyacente por el cual actuamos en adhesión conjunta a una estructura métrica extrínseca.

En otro sitio (Shifres, en prensa) propuse que esa preparación le ha dado los recursos a nuestra cultura musical para elaborar los problemas musicológicos de la ejecución actual de la música para instrumento solo del siglo XIX, que son justamente problemas del tiempo expresivo. Cuando escuchamos música métrica estamos en cierto modo adhiriendo al pulso subyacente de la ejecución. Nuestra experiencia del tiempo se vincula fuertemente (aunque no únicamente) con esa estructura métrica, y por ella nos representamos lo que ya ocurrió, procesamos lo que está ocurriendo y prevemos lo que va a ocurrir. La ruptura que realiza el timing expresivo (rubato) del corsé métrico nos obliga a poner en funcionamiento mecanismos de regulación temporal interactivos más primitivos (Shifres, 2006). En particular, estaría actuando el mecanismo de interacción por tiempo de reacción, que no solamente nos remite a nuestras experiencias interactivas tempranas sino que además nos permite construir un perfil de activación de la conducta del otro en el tiempo (afecto de la vitalidad) capaz de conllevar información emocional dinámica. Por ello, y parafraseando a Ricouer (1985) decimos que la ejecución musical se configura estructuralmente con el fin de ofrecer al oyente un conjunto de experiencias temporales "para compartir". De este modo, la ejecución define axiomáticamente una intencionalidad temporalmente interactiva.

A pesar de que parecería no existir conductas interactivas por parte del oyente es importante tener en cuenta que la clave del éxito que tan sutiles microvariaciones en la organización temporal tiene sobre la experiencia de la obra de arte, se basa en el compromiso corporal del oyente, como observador real o virtual, del ejecutante (Clarke, 1998; Gallese, 2001). La música así, coordina las percepciones y las expectativas que gobiernan las acciones, en una suerte de percepción kinética (Keil, en Clayton, Sagel y Hill, 2004). Esto permitiría que las interacciones cara a cara puedan ser sustituidas por situaciones artificiales particulares tales como ciertas experiencias de contemplación artística (como lo propone Gomila, 2003 , cita véase arriba).

La evidencia de la experiencia transmodal de la música, pone de manifiesto el hecho de que en la ejecución musical como fenómeno intersubjetivo las personas no comparten notas musicales sino tipos de configuraciones temporales modeladas por esas notas entre muchos otros componentes. La fuerza del lazo ceñido en esa comunicación obedece a esa única, particular e irrepetible configuración del tiempo. Un tiempo que ejecutantes y oyentes danzamos para regocijo de todos los sentidos.

\footnotetext{
Notas

${ }^{1}$ Para una síntesis de las perspectivas de intersubjetividad basadas en la Teoría de la Teoría, denominada de tercera persona, y en la Teoría de la Simulación, denominada de primera persona, véase Gallagher, 2001 y Thompson, 2001)

${ }^{2}$ Es importante aclarar que Stern (1985, p. 179) diferencia el fenómeno de entonamiento de la experiencia de intersubjetividad tal como es propuesta por Trevarthen señalando que éste último la confina a una suerte de interintencionalidad (compartir intenciones y motivos) mientras que su concepto se refiere más bien a una interafectividad (compartir el carácter del sentimiento). Sin embargo la perspectiva de segunda persona, tal como la estamos considerando aquí no solamente admite sino que también requiere de ese componente de interafectividad.
} 


\section{Referencias}

BJÖRLING, D. (2002). Chopin and the G minor Ballade. D-uppsats Musik, 2002:01, 1-55.

Boltz, M. (1992). Temporal Accent Structure and the Remembering of Filmed Narratives. Journal of Experimental Psychology: Human Perception and Performance, 18 (1), 90-105.

Clarke, E. F. (1998). The semiotics of expression in musical performance. Contemporary Music Review, 17 (2), 87-102.

Clayton, M., SAGel, R \& Hill, U. (2004). In time with the music: The concept of entrainment and its significance for ethnomusicology. ESEM Counter point, 1, 1-45

CLYNes, M. (1983). Expressive microstructure in music, linked to living qualities. En J. Sundberg (Ed.), Studies of Music Performance (pp. 76-181). Estocolmo: Royal Swedish Academy of Music.

Collho, N. E. \& Figueiredo, L. C. (2003). Patterns of Intersubjectivity in the Constitution of Subjectivity: Dimension of Otherness. Culture E Psychology, 9 (3), 193-208.

Cook, N. (1990). Music, Imagination and Culture. Oxford: Oxford University Press.

CoOK, N. (1998). Analysing Music Multimedia. Oxford: University Press.

DeliÈGe, C. (2000). The music work as discourse an text. Musica Scientice, IV (2), 213-225.

Español, S. \& Shifres, F. (2003). Música, Gesto y Danza en el segundo año de vida. Consideraciones para su estudio. En I. Martínez \& C. Mauleón (Eds.), Música y Ciencia. El rol de la Cultura y la Educación en el Desarrollo de la Cognición Musical (Actas de la III Reunión Anual de SACCoM). La Plata: SACCoM. CD-ROM.

Evans, V. (2005). The structure of time. Amsterdam y Philadelphia: John Benjamins Publishing Company.

GABrielsson, A. (2001). Emotions in strong experiences with music. En P. Juslin \& J. Sloboda (Eds.), Music and Emotion. Theory and Research (pp. 431-449). Oxford: Oxford University Press.

Gallagher, S. (2001). The practice of Mind: Theory, Simulation or Interaction? Journal of Consciousness Studies, 8 (5-7), 83108.

GaLlese, V. (2001). The "Shared Manifold" Hypothesis. Journal of Consciousness Studies, 8 (5-7), 33-50.

Gomila, A. (2003). La perspectiva de la segunda persona de atribución mental. En A. Duarte \& E. Rabossi (Eds.), Psicología cognitiva y filosofía de la mente (pp. 195-218). Buenos Aires: Alianza.

Hargreaves, D. J., MacDonald, R. \& Miell, D. (2005). How do people communicate using music? En D. Meill, R. MacDonald \& D. Hargreaves (Eds.), Musical Communication (pp. 1-25). Oxford: Oxford University Press.

Imberty, M. (1997). Peut-on parler sérieusement de narrativité en musique? En Alf Gabrielsson (Ed.), Proceedings of the Third Triennial ESCOM Conference (pp. 23-32). Uppsala: University of Uppsala.

JAMESON, J. \& GENTNER, D. (2003). Mundane comparisons can facilitate relational understanding. Proceedings of the Twentyfifth Annual Meeting of the Cognitive Science Society.

JusLin, P. N. (1997). Emotional communication in Music Performance: A Funtionalist Perspective and Some Data. Music Perception, 14 (4), 383-418.

JusLin, P. N. (2005). From mimesis to catharsis:expression, perception, and induction of emotion in music. En D. Meill, R. MacDonald \& D. Hargreaves (Eds.), Musical Communication (pp. 85-115). Oxford: Oxford University Press.

Kendall, R. A. \& CARterette, E. C. (1990). The Communication of Musical Expression. Music Perception, 8 (2), 129-164.

KLEIN, M. (2004). Chopin's Fourth Ballade as Musical Narrative. Music Theory Spectrum, 26, 23-55.

LERDAHL, F. (2001). Tonal Pitch Space. Oxford: University Press.

LERDAHL, F. \& JACKENDOFF, R. (1983). A Generative Theory of Tonal Music. Cambridge, MA: The MIT Press.

LEWKOWICZ, D. J. (1992). Infants' response to temporally-based intersensory equivalence: The effect of synchronous sounds on visual preferences for moving stimuli. Infant Behavior and Development, 15, 297-324

LEWKOWICZ, D. J. \& KRAEBEL, K. (2004). The value of multimodal redundancy in the development of intersensory perception. En G. Calvert, C. Spence \& B. Stein (Eds.), Handbook of multisensory processing. MIT Press.

LIPSCOMB, S. D. \& TolCHINSKY, D. E. (2005). The role of music communication in cinema. En D. Meill, R. MacDonald \& D. Hargreaves (Eds.) Musical Communication (pp. 383-404). Oxford: University Press.

Merker, B. (2002). Principles of Interactive Behavioral Timing. En C Stevens, D. Burham, G. McPherson, E. Schubert \& J. Renwick (Eds.), Proceedings of the 7th International Conference of Music Perception and Cognition (pp. 149-152). Sydney: University of Western Sydney.

Nattiez, J. J. (1990). Can one speak of Narrativity in Music? Journal of the Royal Musical Association, 115 (2), $240-257$.

Palmer, C. (1997). Music Performance. Annual Review of Psychology, 48, 115-138.

PAPOUSEE, M. (1996). Intuitive parenting: a hidden source of musical stimulation in infancy. En I. Deliège \& J. A. Sloboda (Eds.), Musical Beginnings. Origins and Development of Musical Competence (pp. 88-112). Oxford: University Press.

Repp, B. H. (1992). Diversity and commonality in music performance: An analysis of timing microstructure in Schumann's "Traumerei". Journal of The Acoustical Society of America, 92 (5), 2546-2568.

Repp, B. H. (1998). A microcosm of musical expression. I. Quantitative analysis of pianists' timing in the initial measures of Chopin's Etude in E major. Journal of The Acoustical Society of America, 104 (2), 1085-1100.

ReybroucK, M. (2003). Biological roots of musical epistemology. Functional cycles, Umwelt, and enactive listening. Semiotica, $134(1 / 4), 599-633$.

Ricouer, P. (1984). Temps et rècit. II: la configuration dans le récit de fiction. París: Éditions du Seuil. [Tiempo y Narración II. La configuración del tiempo en el relato de ficción (A. Neira, trans.). México: Siglo XXI, 2001].

Ricouer, P. (1985). Temps et rècit. I: l'bistoire et le rècit París: Éditions du Seuil. [Tiempo y Narración I. La configuración del tiempo en el relato bistórico (A. Neira, trans.). México: Siglo XXI, 2003].

Rothsthein, W. (1995). Analysis and the act of performance. En J. Rink (Ed.), The Practice of Performance. Studies in musical interpretation (pp. 217-240). Cambridge: University Press.

Samson, J. (1992). Chopin: The Four Ballades. Cambridge: University Press.

SCHenker, H. (1935). Der freie Satz. Wien: Universal Edition. [Free composition, (E. Oster, trans.). Nueva York: Schirmer Books, 1979].

SHANKer, S. G. \& KING, B. J. (2002). The emergence of a new paradigm in ape language research. Behavioral and Brain Sciences, $25(5), 605-620$.

SHANNON, C. E. \& WEAVER, W. (1949). The mathematical theory of communication. Urbana: University of Illinois. 
SHIFRes, F. (2006). Tocar Juntos: ¿Entrainment, comunicación o comunión? En F. Shifres \& G. Vargas (Eds.), Sonido, Imagen y Movimiento en la Experiencia Musical (pp. 189-203). Buenos Aires: SACCoM.

SHIFRES, F. (en prensa). El tiempo musical: de nuestra dimensión perdida a la encrucijada entre performance, evolución y desarrollo. Revista del Instituto de Investigación Musicológica "Carlos Vega".

SHIFRES, F. \& ESPAÑOL. S. (2004). Interplay between pretend and music play. Trabajo aceptado para la $8^{\text {th }}$ International Conference on Music Perception \& Cognition, Evanston, IL..USA.

SimeON, E. (1992). Programmi narrative e stratificazioni del senso nella musica per film. Il caso di "Entr'acte". En R. Dalmonte \& M. Baroni (Eds.), Atti di Secondo Convegno Europeo di Analisi Musicale (pp. 389-399). Trento: Universita degli Studi di Trento.

Small, C. (1999). El musicar. Un ritual en el espacio social. Revista Transcultural de Música. Transcultural Music Review, 4. En www.sibetrans.com/trans/index.html (página vista el 30.08.2005)

STERn, D. (1985). The interpersonal World of the Infant. A View form Psychoanalysis and Developmental Psychology. Nueva York: Basic Books.

SundBERG, J. (1993). How can music be expressive? Speech Communication, 13, 239-253.

Sundberg, J., Firberg, A. \& FrydÉn, L. (1991). Common Secrets of Musicians and Listeners: An analysis-by-synthesis Study of Musical Performance. En P. Howell, R. West \& I. Cross (Eds.), Representing Musical Structure (pp. 161-197). Londres: Academic Press.

TARASTI, E. (1994). A Theory of Musical Semiotics. Bloomintong e Indianapolis: Indiana University Press.

Thompson, E. (2001). Empathy and Consciousness. Journal of Consciousness Studies, 8 (5-7), 1-32.

Trevarthen, C. (1999/2000). Musicality and the Intrinsic Motive Pulse: evidence from human psychobiology and infant communication. Musica Scientie, Special Issue, 155-213.

WittManN, M. \& PÖPPEL, E. (1999/2000). Temporal mechanisms of the brain as fundamentals of communication - with special reference to music perception and performance. Musica Scientice, Special Issue, 13-28.

\section{Filmografía}

Polansky, R. (2002). The Pianist. Transeuropa Video Entertainment. TVE-IC 023.

\section{Discografía}

Primera Balada en sol menor op. 23 de F. Chopin.

Cortot, A. (1933) Release Date: 12/12/1995 Label: Enterprise Catalog \#:184 Spars Code: ADD.

Horowitz, V. (1968) (Reedited por MK 42306).

Kissin, E. (1999) (BMG 0902663259 2).

Olejnizack, J. (2002) (Sony Music 2-87739) "The pianist" sound track.

Székely, I. (1987) (Lydian 18022) 